\title{
SEQUENCE OF RETURN OF NEUROLOGICAL FUNCTION AND CRITERIA FOR SAFE AMBULATION FOLLOWING SUBARACHNOID BLOCK (SPINAL ANAESTHESIC)
}

\author{
A. Eugene Pflug, Geordis M. Aasheim, and Charlene Foster
}

THERE IS MUCH UNCERTAINTY about the time when it is safe to permit ambulation of patients who have had a subarachnoid block. 1.2 This is due to fear of hypotension and syncope during ambulation, thought to be due to abeyance of sympathetic activation of cardiovascular compensation for changes in body position from supine to erect. The theory is that motor and sensory function return before sympathetic nervous system activity and that this results in hypotension and collapse when early ambulation is attempted. ${ }^{1-3}$

This study examines the sequence of the return of somatic and sympathetic motor and sensory nerve function following subarachnoid block with tetracaine and considers what indices or criteria may be used to assure safe post-operative ambulation of patients who have had subarachnoid block.

\section{METHOD}

Twenty-three adult men were studied during and after subarachnoid block for elective operations. Informed consent was obtained from each patient. They were accepted for study only if there was no infection in the lumbar area of the back and no evidence of hypovolaemia, uncontrolled systemic disease, or history of central nervous system disease. Specific criteria were established as indication for return of motor, sensory and sympathetic nervous activity, and observations were made at specific times both during and after the block. Complete regression of sensory block was determined by return of perianal (sacral 4-5) sensation when tested by response ta pinprick stimulation. Regression of

A. Eugene Pilug, M.D., Geordis M. Aasheim, M.D., and Charlene Foster, R.N., M.S.N. Department of Anesthesiology and the Anesthesia Research Center, University of Washington School of Medicine, Seattle, Washington, 98195.

Request reprints from: A. Eugene Pflug, M.D., Anesthesiology Service. Veterans Administration Hospital, 4435 Beacon Avenue South, Seattle, WA, 98108.

Canad. Anaesth. Soc. J., vol. 25, no. 2, March 1978 motor block was judged by straight leg-raising in the supine position against the resistance of the investigator's hand with a force which in the patient's opinion was equal to his normal strength. Conditions indicating return of sympathetic activity included spontaneous elevation of mean arterial pressure and pulse rate without changes in the patient's position, fluid administration or other treatment; ${ }^{3,4}$ physiological response of these two parameters when the position was changed from supine to standing: $;^{5}$ elevation of tympanic temperature ${ }^{6}$ decrease of peripheral skin temperature measured at the toe;2,6.7 return of autonomic nervous system control of urination; ${ }^{8}$ and decrease of blood flow in the leg. ${ }^{4}$

An intravenous infusion was established in the hand or arm of all the patients, a blood pressure cuff was applied to an arm and each patient was connected to a cardioscope monitor. No premedication was given and all had been fasting for 12 hours. A summary of basic patient characteristics, information related to the subarachnoid block and to the operations are listed in Table I. A standard subarachnoid block was established by the lumbar paramedian approach using a 22gauge needle, with the patient in the left lateral recumbent position. Oxygen was administered by nasal catheter during the operation when indicated by age or disease. Blood loss was measured and was replaced during operation and maintenance fluids were administered with the intent to prevent hypovolaemia. No drug was used to supplement the block in the operating room and observations were completed in the recovery room before any medication was given.

All patients were covered with similar drapes both in the operating room and in the recovery room to avoid the effect of insulation on body temperalure. Room temperature was monitored with a mescury thermometer. * Core body temperature was recorded by tympanic thermistor

*Mercury filled, $20-110^{\circ} \mathrm{C}$ scale, full immersion, 12-inch glass thermometer. Van Waters and Rogers, Seattle, Washington, 98134 . 
TABLE I

\begin{tabular}{|c|c|c|c|c|c|c|}
\hline Pt. No. & $\begin{array}{l}\text { Age } \\
\text { (yrs) }\end{array}$ & $\begin{array}{c}\text { Weight } \\
\text { (kg) }\end{array}$ & $\begin{array}{l}\text { Height } \\
\text { (m) }\end{array}$ & $\begin{array}{c}\text { Tetracaine } \\
\text { (mg) }\end{array}$ & $\begin{array}{c}\text { Level } \\
\text { (Thoracic) }\end{array}$ & Operation \\
\hline 1 & 27 & 91 & 1.75 & 16 & 4 & Inguinal Hernia \\
\hline 2 & 63 & 58 & 1.73 & 8 & 8 & TUR Prostate \\
\hline 3 & 68 & 66 & 1.67 & 15 & 6 & TUR Prostate \\
\hline 4 & 67 & 57 & 1.73 & 10 & 6 & Biopsy Prostate \\
\hline 5 & 65 & 105 & 1.75 & 10 & 5 & Cystoscopy \\
\hline 6 & 63 & 57 & 1.70 & 10 & 6 & Cystoscopy \\
\hline 7 & 27 & 75 & 1.85 & 8 & 7 & Cystoscopy \\
\hline 8 & 69 & 73 & 1.73 & 10 & 7 & TUR Prostate \\
\hline 9 & 81 & 64 & 1.77 & 10 & 5 & TUR Prostate \\
\hline 10 & 57 & 75 & 1.83 & 10 & 10 & TUR Prostate \\
\hline 11 & 42 & 82 & - & - & 9 & Inguinal Hernia \\
\hline 12 & 83 & 81 & 1.85 & 12 & 8 & TUR Prostate \\
\hline 13 & 20 & 68 & 1.73 & 8 & 6 & Cystoscopy \\
\hline 14 & 55 & 95 & 1.80 & 10 & 6 & Cystoscopy \\
\hline 15 & 62 & 58 & 1.67 & 8 & 5 & Cystoscopy \\
\hline 16 & 67 & 95 & 1.83 & 10 & 6 & TUR Prostate \\
\hline 17 & 53 & 68 & 1.77 & - & 8 & Hemorrhoidectomy \\
\hline 18 & 58 & 90 & 1.90 & 15 & 5 & TUR Bladder \\
\hline 19 & 77 & 75 & 1.70 & 15 & 8 & TUR Prostate \\
\hline 20 & 38 & 85 & 1.80 & 10 & 5 & Cystoscopy \\
\hline 21 & 61 & 91 & 1.95 & 10 & 8 & Cystoscopy \\
\hline 22 & 62 & 83 & 1.80 & - & 6 & Cystoscopy \\
\hline 23 & 63 & 87 & 1.83 & 20 & 5 & TUR Prostate \\
\hline$\overline{\mathbf{X}}$ & 57.7 & 77.3 & 1.78 & 11.3 & 6.5 & \\
\hline SD & 16.7 & 13.9 & 0.07 & 3.2 & 1.5 & \\
\hline SE & 3.6 & 3.0 & 0.02 & 0.7 & 0.3 & \\
\hline
\end{tabular}

probes (Surg-a-temp, Arlbrook Inc., Arlington, Texas) and peripheral temperature with a skin thermistor probe applied to the big toe (Yellow Springs Instruments Co. Probes). All of these temperature measuring devices were calibrated in a water bath against the mercury thermometer.* The thermistor probe on the great toe was placed on the plantar surface, covered with a folded $4 \times 4$-inch gauze pad and attached securely with cloth tape. Blood pressure and pulse were measured and recorded by the same investigator using the same equipment for all patients. Mean arterial pressure was calculated as the diastolic pressure plus one-third of the pulse pressure. Blood flow in the leg was measured by venous occlusive plethysmography while the patient was breathing room air, to avoid the peripheral vasopressor effect of 100 per cent oxygen. 9 These blood flow measurements were obtained at the time of closure of the surgical incision or following removal of the legs from stirrups (TURP) and after complete regression of the subarachnoid block, as defined. A Hokanson model EC-I plethysmograph was used which included a mercury-in-rubber strain gauge applied to the calf of the leg, a contoured blood pressure cuff to the thigh and an electronically operated pneumatic cuff inflator to provide uniform inflation with each measurement. Each reading was recorded with a brush pen recorder. Results are stated as percentage of increase in limb blood flow or limb volume in millilitres per $100 \mathrm{cc}$ tissue/minute. The validity of this method has been documented by radioactive [ $^{131}$ direct flow measurements. ${ }^{13}$

Measurements of mean arterial pressure, pulse rate, room, tympanic and toe temperatures were obtained every 30 minutes both during the operation and in the recovery room until regression of anaesthesia was complete. Neurological examination for return of motor and sensory function was done in the recovery room at 30 -minute intervals. After the criteria for complete regression of the block had been fulfilled, the patient was asked to sit upright for five minutes and then to stand for five minutes. Blood pressure and pulse were obtained at the end of each five-minute period. Patients were steadied while upright but stood under their own power.

Statistical significance was determined by t-test for paired observations.

\section{RESULTS}

Table I shows the physical characteristics of the 23 men who had subarachnoid block for routine elective operations. The dose of tetra- 
TEMPERATURE $\left({ }^{\circ} \mathrm{C}\right)$
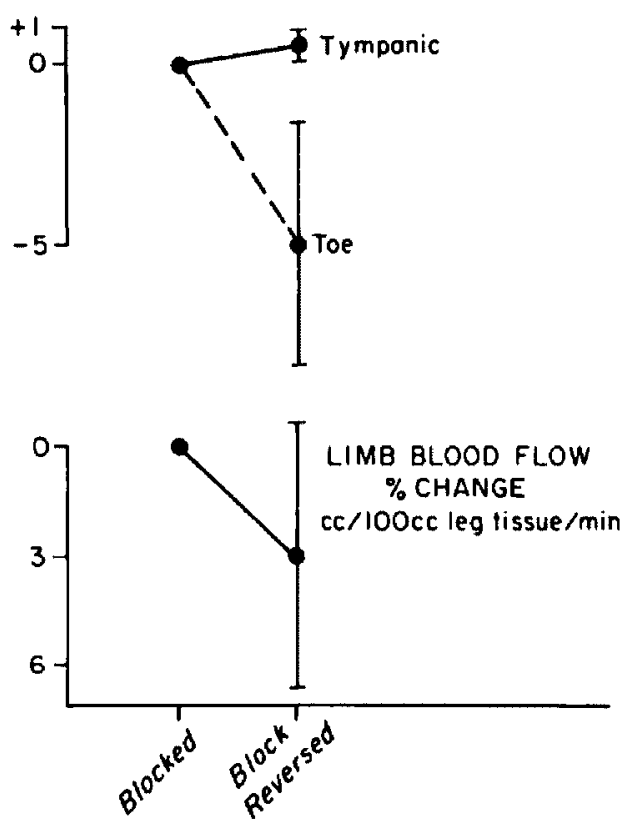

FIGURE I Changes in body temperature and leg limb blood flow with regression of spinal block, mean values $\pm \mathrm{SD}$.

caine without vasopressor varied from 8 to 20 milligrams and the thoracic dermatome level of anaesthesia as determined by pinprick varied from T-4 to T-10.

Figure 1 shows body temperatures during anaesthesia. As the block regressed peripheral (big toe) skin temperature uniformly decreased from a mean of $34.1^{\circ}$ to $29.1^{\circ} \mathrm{C}(\mathrm{p}<0.001)$ and core body (tympanic) temperature increased from a mean of $35.9^{\circ}$ to $36.5^{\circ} \mathrm{C}(\mathrm{p}<0.001)$. Room or ambient temperature showed little change over this period of about two hours.

Cardiovascular parameters during regression of subarachnoid block (Figures 1 and 2) also showed consistent trends. Mean arterial pressure values, both individual and mean, progressively increased with time, from 80.1 to $99.9 \mathrm{~mm} \mathrm{Hg}$ (p $<0.001$ ) when comparing pressures during the block with those when the patient was standing after the block had completely worn off. Pulse changes were less uniform, but the rate also progressively increased, the comparable figures being 68.8 to 72.2 and 68.8 to 82.1 beats per minute, differences which are not statistically significant. Under the same conditions leg blood flow values decreased consistently, providing another indication of vascular changes with regression of the block. Mean limb blood flow was 6.7 during subarachnoid block and decreased to $3.6 \mathrm{ml}$ per $100 \mathrm{cc}$ of tissue/minute $(\mathrm{p}<0.001)$ after regression of the block but before the patient was allowed to stand up.

Table II and Figures 1 and 2 give a summary of the physical changes noted and are correlated with the neurological status at the time of standing and walking. Of the 23 men studied, 17 were able to stand alone at the time when they met our criteria for regression of subarachnoid block. Six of the 23 showed obvious lower leg weakness that did not allow ambulation. These patients later admitted over-estimation of leg strength when it was tested in the supine position. However, none of the 23 patients became faint or hypotensive on change of position from supine to upright and no post-spinal headache was reported. Two of the 17 patients who could stand had no motor weakness. The remaining 15 patients who could stand were ataxic and complained of "not knowing where their feet were in space" (lack of proprioception)

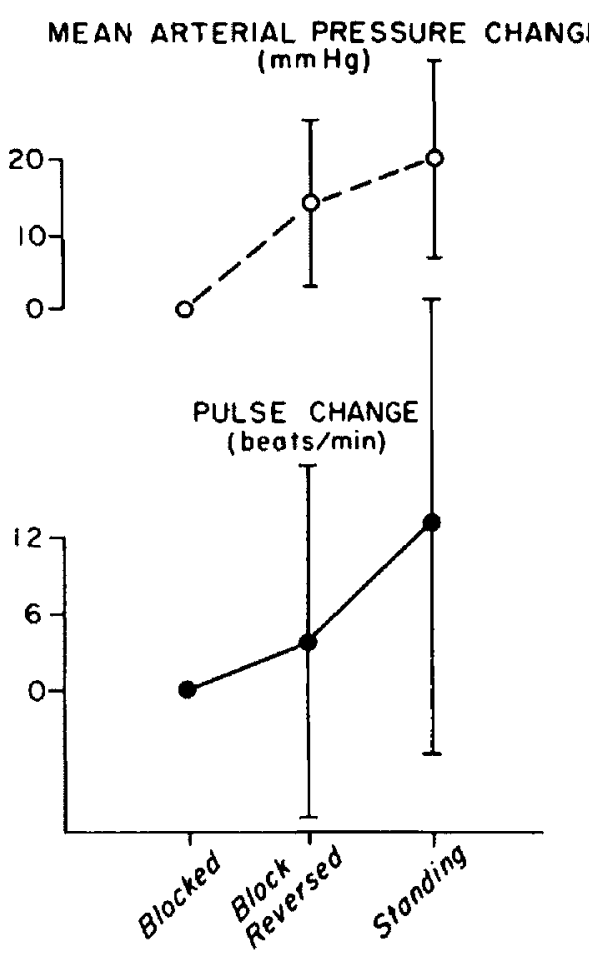

Figure 2 Changes in mean arterial pressure and pulse with regression of spinal block, mean values \pm SD. 
or could not stand on the anterior portion of their feet, lifting their heels from the floor (Gastrocnemius and Soleus muscle weakness). Five of the patients were able to urinate.

Thus 21 of 23 patients had demonstrated somatic sensory and/or motor neurological deficit after a return, by our criteria, of sympathetic nervous system activity. The sequence of return of neurological activity after subarachnoid block anesthesia was sympathetic activity, pinprick sensation, somatic motor activity followed finally by proprioception in the feet.

\section{Discussion}

Measurement of cardiovascular responses, body temperature and control of certain body functions during subarachnoid block may result in variable values depending on the area of anaesthesia, fluid volume status, body position during operation, nature of the operation and drugs administered during anaesthesia and recovery. These extraneous factors were controlled or eliminated during this study whenever possible.

Skin temperature of the great toe was used to represent peripheral temperature for several reasons. Past studies have utilized toe temperatures as an index of cardiovascular status during traumatic conditions such as burns ${ }^{10}$ and shock 11 and to quantify cutaneous blood flow. ${ }^{12}$ This same method might also apply to major surgery. ${ }^{7}$ Temperature of the skin of the big toe depends almost entirely on cutaneous blood flow since there is no insulation effect or metabolism in adjacent tissues which might alter the temperature of the skin over other areas of the body (fat insulation, muscle metabolism). The gauze pad covering the temperature probe over the big toe efficiently limits rapid changes due to sudden alterations in ambient conditions which could influence heat loss from evaporation, convection or radiation. Skin temperature helps regulate core body temperature by increasing or decreasing body insulation through vasoconstriction and vasodilation respectively. ${ }^{6}$ This vasomotor activity depends on function of the sympathetic nervous system. ${ }^{4}$ Changes in skin temperature therefore provide a good index of changes in sympathetic activity (Table II, Figure 1). Changes in core body temperature are also a homeostatic function of sympathetic nervous system activity. 4.6

Subarachnoid block anaesthesia is accompanied by a decrease in mean arterial pressure and pulse rate in most cases, which are usually proportional to the area of anaesthesia. ${ }^{3}$ This hypotension is due to sympathetic nervous system paralysis. ${ }^{3,4}$ Spontaneous elevation of mean arterial blood pressure and pulse rate without changes in position, fluid balance or therapy is assumed to indicate reversal of sympathetic paralysis (Table II, Figures 1 and 2). Decrease of limb blood flow is also used as an indication of such reversal, based on the reported effect of sympathetic activity on blood flow. ${ }^{4}$

Ziegler and associates ${ }^{5}$ recently studied the physiologic response of mean arterial blood pressure and pulse rate when normal subjects change position from supine to standing. They reported that after standing for five minutes, subjects did not show any change of blood pressure, but had a mean rise of 20 beats per minute in pulse rate. These cardiovascular changes were accompanied by a simultaneous increase in plasma levels of norepinephrine and dopamine-betahydroxylase. Increased plasma levels of norepinephrine indicate increased sympathetic activity. ${ }^{5}$ Therefore an increase in pulse rate and a stable mean arterial pressure on changing position from supine to standing is assumed to indicate increased sympathetic nervous system activity (Table II, Figure 2). Final indication of reversal of sympathetic paralysis is the ability to urinate, since an intact functioning sympathetic nerve supply to bladder and urethra is necessary for this function. ${ }^{8}$

All six indicators showed recovery of sympathetic activity at a time when regression of the subarachnoid block was not complete as judged by lower leg motor weakness and lack of proprioception in the feet.

The sequence of return of neurological activity after subarachnoid block anaesthesia found during this study was sympathetic activity first, then pinprick sensation, followed by somatic motor muscle strength and, last, proprioception in the feet. The sequence of return of function classically reported is motor, then sensory and sympathetic activity last. ${ }^{3}$ Daos and Virtue' studied 54 patients who had subarachnoid block anaesthesia and found by psychogalvanic reflex testing that about half showed return of sympathetic activity before sensory or motor sunction. Roe and $\mathrm{Cohn}^{2}$ studied five patients by correlating return of pinprick and thermosensory sensation with changes in core and peripheral temperatures. Temperature was used as an index of sympathetic activity. They found in all patients that sympathetic activity returned before complete thermosensory and pinprick sensation. 


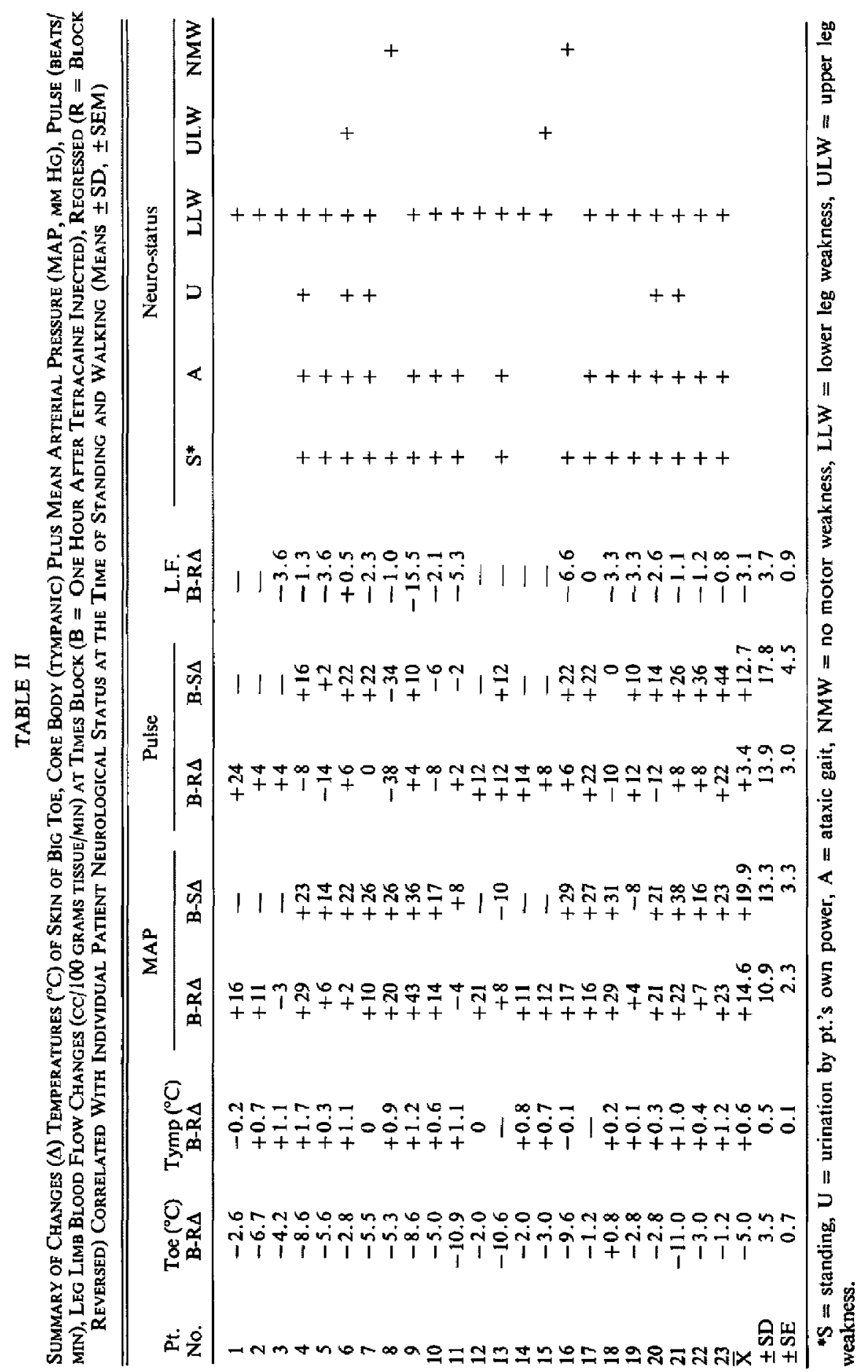


From the evidence found in this study we recommend that the following clinical criteria be used for determining the time when ambulation may safely be permitted for patients who have had a subarachnoid block: (1) return of pinprick sensation in the peri-anal area (sacral 4-5); (2) plantar flexion of the foot (while supine) at preanaesthetic levels of strength; (3) return of proprioception in the big toe. These criteria apply if the patient is not hypovolaemic or sedated with drugs. From the evidence found during this study, we also conclude that the sequence of regression following tetracaine subarachnoid block is sympathetic nervous system activity, somatic sensory (pinprick sensation), then motor activity and finally proprioception in the feet.

\section{SUMMARY}

Twenty-three adult men were studied during and after subarachnoid block anaesthesia for elective surgery. Measurements were obtained of mean arterial pressure and pulse, both supine and after standing for five minutes, core body (tympanic) and peripheral skin (toe) temperatures and blood flow in the leg. Time of measurements included one hour after the injection of tetracaine and after regression of the block. Results obtained indicate that the sequence of return of neurological activity following tetracaine subarachnoid block is sympathetic nervous system activity, pinprick sensation, somatic motor function followed by proprioception in the feet. This progression provides the basis for recommended criteria which indicate when it is safe for patients who have had subarachnoid block anaesthesia to become ambulatory. These criteria include: (1) return of pinprick sensation in the peri-anal area (sacral 4-5); (2) plantar flexion of the foot (while supine) at pre-anaesthetic levels of strength; and (3) return of proprioception in the big toe, always provided that the patient is not hypovolaemic or sedated.

\section{RÉSUMÉ}

Les auteurs ont soumis 23 adultes consentants à une étude visant à déterminer l'ordre de retour des fonctions sympathiques, sensitives et motrices, après anesthésie sous-arachnoüdienne et à rechercher des critères permettant à ces patients de reprendre la station debout en toute sécurité. A ces fins, ils ont effectué des mesures de fréquence cardiaque et de pression artérielle moyenne en position couchée et après cinq minutes de station debout, de température centrale (tympanique) et cutanée périphérique (gros orteil), ainsi que des mesures de débit sanguin au membre inférieur. Ces mesures ont été faites durant et après le bloc, à l'exception des mesures en station debout qui n'ont été effectuées que lorsque les critères de récupération du bloc étaient satisfaits.

Les résultats indiquent la séquence suivante dans le retour des fonctions neurologiques après bloc sous-arachnoïdien à la tétracaîne: activité sympathique, sensibilité à la piqure d'aiguille, motricité et, enfin, proprioception au niveau des pieds. Cette séquence d'événements permet de préciser les critères nous indiquant le moment où nous pouvons permettre avec sècurité aux patients de redevenir ambulants après rachi-anesthésie.

Ces critères incluent: (1) Retour de la sensibilité à l'aiguille dans la région péri-anale $\left(S_{4}-S_{5}\right)$. (2) Flexion plantaire du pied en position couchée et ceci au niveau de force pré-anesthésique. (3) Retour de la fonction proprioceptive au gros orteil. Tout ceci en autant que le malade n'est pas sous sédation ou hypovolémique.

\section{ACKNOWLEDGEMENTS}

The authors wish to thank Ms. Kathleen Lewis, Ms. Willie Tanner, and Ms. Irene Cressey for their skillful technical assistance and Ms. Ruth Claus for her editing and typing. This study was supported in part by Grant RR-133 from the General Clinical Research Center of the Division of Research Resources, National Institute of Health and by a grant from The Parker B. Francis Foundation, Kansas City, Missouri.

\section{REFERENCES}

1. Daos, F.G. \& Virtue, R.W. Sympathetic-Block persistence after spinal or epidural analgesia. JAMA $183: 285$ (1963).

2. RoE, C.F. \& Corn, F.L. Sympathetic blockade during spinal ane sthesia. Surg., Gyn. Obs. 136:265 (1973).

3. Goodman, L.S. \& Guman, A. The pharmacological basis of therapeutics, 5th edition, New York, Macmillan, pp. 395 \& 396 (1975).

4. Goodman, L.S. \& Gilman, A. The pharmacological basis of therapeutics, Sth edition, New York, Macmillan, p. 408 (1975).

5. Ziegler, M.G., Lake, C.R., \& Kopin, I.J Deficient sympathetic nervous response in familial dysautonomia. New Engl. J. Med. 294: 630 (1976).

6. RuCH, T.C. \& PATTon, H.D. Physiology and Biophysics, 20th edition, Philadelphia, Saunders (1973), Vol. Ill, p. 123. 
7. Eberhart, R.C. \& Trezek, G.J. Central and peripheral rewarming patterns in post-operative cardiac patients. Critical Care Med. $1: 239$ (1973).

8. KhanNa, O.P. Disorders of micturition. Urology $8: 316(1976)$

9. Ward, R.J., Danziger, F., AKamatsu, $T$. Freund, F., \& Bonica, J.J. Cardiovascular response of oxygen therapy for hypotension of re gional anesthesia. Anesth \& Analg 45: 140 (1966).

10. Buwalda, G. Thermographic assessment of burns and frostbite. Bibl. Radiol. 5 ; 178 (1969)
11. JOLY, H.R. \& WEIL, M.H. Temperature of the great toe as an indication of the severity of shock. Circulation 39: 131 (1969).

12. Burton, A.C. The range and variability of the blood flow in the human fingers and vasomotor regulation of the body temperature. Am. J. Physiol. 127: 437 (1939).

13. Formel, P.F.\& Doy 2 , J.T. Rationale of venous occlusion plethysmography. Circulat. Res. 5: 354 (1957). 